\title{
Assessing the State of Comprehensive Medication Management in a Sample of Primary Care Clinics
}

Deborah L. Pestka, PharmD, PhD'; Lindsay A. Sorge, PharmD, MPH, BCACP ${ }^{1}$; Jordan Mendkoff'; Caitlin K. Frail, PharmD, MS, BCACP';

Kylee A. Funk, PharmD, BCPS ; Jennifer K. Carroll, MD, MPH'; Todd D. Sorensen, PharmD ${ }^{1}$; Mary T. Roth McClurg, PharmD, MHS ${ }^{3}$

${ }^{1}$ College of Pharmacy University of Minnesota; ${ }^{2}$ University of Colorado School of Medicine; ${ }^{3}$ University of North Carolina Eshelman

School of Pharmacy

\section{OVERVIEW}

Comprehensive medication management (CMM) is an important tool to address medication-related morbidity and mortality and reduce health care costs. Medication therapy problems (MTPs) are a significant and costly barrier to improving patient outcomes ${ }^{1}$ and with more than half of all Americans taking at least one prescription drug, ${ }^{2}$ the need to manage and optimize patients' medications is greater than ever.

This report examines select practice and practitioner characteristics of the primary care clinics that participated in the research project, Enhancing Performance in Primary Care Medical Practice through Implementation of Comprehensive Medication Management. To be eligible to participate, sites had to have: established relationships with care team providers, a way of electronically identifying patients most in need of CMM, reporting processes in place for CMM data, read/write access in the electronic medical record, and an established CMM practice or a commitment to providing CMM. Because of these inclusion criteria, most participating clinics had CMM services in place for several years and were mature in their design and delivery of services.

Site characteristics around the following areas were assessed: pharmacist and clinic demographics, delivery of pharmacy services, collaboration, billing and payment for CMM, and measuring CMM outcomes. The results of this report shed light on how CMM is being delivered in a sample of established CMM practices and therefore may provide benefit to those practitioners interested in building their own CMM practice.

\section{BACKGROUND}

A growing concern in health care in the United States is the rising costs attributed to prescription drug use. In 2015, prescription drug spending accounted for $10.1 \%$ of the $\$ 3.2$ trillion spent on total national health expenditures. ${ }^{3}$ In 2018 , it was reported that health care costs caused by improper and unnecessary use of medicines exceed $\$ 500$ billion per year. ${ }^{1}$ Correcting this issue and optimizing medication use is critical to help our country improve health care at lower costs.

As our health care system expands adoption of compensation systems rooted in demonstration of value, it is of utmost importance that pharmacy leaders define and share the value of comprehensive medication management (CMM) services as a key component of team-based care. Clinical pharmacists are best equipped to work collaboratively with other health care providers to improve medication use through the provision of $\mathrm{CMM}^{4,5}$

CMM is the practice of individualized patient care to ensure that each medication a patient is taking is appropriate, effective for the indicated condition, safe for the patient, and able to be taken by the patient as intended. ${ }^{6,7} \mathrm{CMM}$ involves the assessment of a patient and development of an individualized care plan to achieve the intended goals of therapy with appropriate follow-up to determine patient outcomes. ${ }^{6,7} \mathrm{CMM}$ includes a follow-up evaluation to ensure the patient is meeting their goals for their medication therapy. A requirement of $\mathrm{CMM}$ is collaboration among the various members of the health care team. ${ }^{8}$ Many primary care clinics offer this service, but it is unclear how closely providers adhere to this definition of CMM.

The literature has discussed the need for a consistent pharmacist patient care process (PPCP). ${ }^{9-12}$ The landmark model proposed by the Joint Commission of Pharmacy Practitioners outlined the recommended PPCP that pharmacists should adhere to in caring for patients. ${ }^{11}$ This work was significant because of the endorsement by multiple pharmacy organizations. While there is now general agreement on the elements of the PPCP, no known literature exists examining how closely pharmacists are following the PPCP in practice.

Corresponding author: Deborah L. Pestka, PharmD, PhD

College of Pharmacy University of Minnesota

Email: pestk003@umn.edu 


\section{The CMM Primary Care Study}

This work was supported by the grant Enhancing Performance in Primary Care Medical Practice through Implementation of Comprehensive Medication Management funded by the American College of Clinical Pharmacy (ACCP) and the ACCP Foundation. The project was led by the University of North Carolina Eshelman School of Pharmacy, the University of Minnesota College of Pharmacy, the American Academy of Family Physicians (AAFP) National Research Network, and the Alliance for Integrated Medication Management (AIMM). The aims of the research were:

AIM 1: Assess baseline demographics, state of CMM within each practice, and practitioner and organizational readiness and capacity for CMM service development, refinement, and expansion.

AIM 2: Determine best practices in the design and delivery of CMM in primary care that optimize medication use (i.e., how CMM is best delivered to patients in primary care).

AIM 3: Determine the structural and system-level elements (i.e., the practice management system) that are needed to support the effective and efficient delivery of CMM and establish initial benchmarks for practice quality and efficiency.

AIM 4: Determine the key performance measures that support the value proposition for CMM from the perspective of stakeholders internal and external to the providing organization, and evaluate performance of study sites individually and collectively according to these key measures.

AIM 5: Accelerate the adoption of CMM best practices through (a) replication across the study sites; (b) dissemination across a facilitated community of learning to primary care

Study activities were carried out between January 2016 and June 2018.

\section{Identifying the Study Sites}

Per the expectations set by the funder via the original request for proposal announcement, sites included in the study were required to have well-established CMM services delivered by pharmacists embedded in the primary care clinic and acknowledge that they were offering CMM, as defined in the ACCP Standards of Practice for Clinical Pharmacists ${ }^{4}$ and the Patient-Centered Primary Care Collaborative Comprehensive Medication Management Resource Guide. ${ }^{7}$ These documents outline steps to provide CMM as well as the expectations for clinical pharmacists delivering the service. Participating clinics were recruited by the University of Minnesota, the University of North Carolina, and the AAFP National Research Network. The University of Minnesota and the University of North Carolina both recruited a diverse group of primary care sites with which they had existing relationships. AAFP put out a national call to members of the AAFP National Research Network to participate in the study and those who responded and met the inclusion criteria were included in the study. To meet the minimum eligibility requirements, all sites needed to:

- Be part of existing primary care medical practices

- $\quad$ Represent a diversity of primary care sites (e.g., community-based health centers, safety net clinics, independent primary care clinics)

- Have established team-based relationships where clinical pharmacists are authorized by collaborative practice agreements (CPAs) and/or by a documented privileging process to engage in patient encounters

- Have an electronic patient registry or a means of identifying patients most in need of CMM

- Have read/write access for the clinical pharmacists in the electronic medical records (EMR)

- Have an existing approach to reporting quality measures on a regular basis for practice improvement (e.g., hospitalizations, emergency department visits, clinical care gaps, clinic revenue)

- $\quad$ Provide or have the commitment to provide CMM services in accordance with ACCP standards ${ }^{4}$ regarding care process and documentation and in the context of team-based care delivery

\section{Aims of this Report}

The purpose of this report is to present the findings of Aim 1 where the baseline demographics and the state of CMM within each practice were assessed. Pharmacy practitioners and administrators frequently seek guidance on building CMM practices and understanding of how other sites are delivering CMM services. This is evidenced by the frequent inquiries for this type of information posted on professional listservs such as the American College of Clinical Pharmacy (ACCP) Ambulatory Care PRN, American Society of Health-System Pharmacists (ASHP) Connect, American Pharmacists Association (APhA) ENGAGE, among others. Therefore, this report was created to:

1. Provide a snapshot of CMM practice among a sample of mature primary care clinics currently delivering CMM.

2. Describe the baseline status of CMM service delivery across sites enrolled in the Enhancing Performance in Primary Care Medical Practice through Implementation of Comprehensive Medication Management study.

3. Provide an overview for those practitioners interested in building a CMM practice to guide care delivery and practice management. 


\section{METHODS}

\section{Survey Design}

Two separate surveys were administered: a demographics survey and baseline survey. The demographics survey addressed both pharmacist-level and practice-level demographic questions. The demographics survey consisted of 70 questions; however, response logic limited the total number of questions for individual participants.

The baseline survey addressed seven domains: clinic demographics, pharmacy services, clinic resources for providing CMM, measuring outcomes and quality assurance related to CMM, the pharmacy team, creating a shared vision around CMM, and collaboration within the clinic. These domains were chosen based on the content expertise of the research team, as well as a review of resources previously shared via professional societies and other publicly available reports. ${ }^{4,13-18}$ The baseline survey was 80 questions.

Both the demographic and baseline survey were reviewed by a survey research consultant at the University of North Carolina who provided feedback and suggestions for improvement on survey structure and items. The baseline survey was pilot tested by four clinical pharmacists practicing in ambulatory care settings May - June 2016. The purpose of the pilot was to gain feedback on the terminology used throughout the survey, ensure that the items were clear and could be answered by participants, as well as to provide any overall feedback on the survey. The survey questions were modified based on pilot tester feedback.

Both the demographic and baseline surveys were built into Qualtrics (Qualtrics, Provo, UT) and administered via email to the lead pharmacist of all participating clinics in August 2016. Participants were asked to complete the surveys within two weeks, and were sent up to three reminders, if necessary.

Two clinics were added to the study in October 2016 and sent the baseline and demographic surveys at that time. In total, 40 clinics completed the CMM demographic and baseline surveys. Results were analyzed descriptively in Microsoft Excel.

\section{RESULTS}

\section{Pharmacist and Clinic Demographics}

Table 1 presents relevant demographic information of the lead pharmacists from each of the participating clinics. Most pharmacists had a Doctor of Pharmacy degree, had completed a pharmacy residency, and had obtained at least one board of pharmacy certification.

Table 1. Demographics of lead pharmacist $(\mathbf{n = 4 0 )}$ at participating sites
\begin{tabular}{|ll|}
\hline Characteristic & N (\%) \\
Pharmacy degree(s) & $36(90 \%)$ \\
PharmD & $4(10 \%)$ \\
BS Pharm and PharmD & \\
Additional post-graduate training completed & $33(82.5 \%)$ \\
PGY1 & $5(12.5 \%)$ \\
PGY2 & $1(2.5 \%)$ \\
Fellowship & $1(2.5 \%)$ \\
MBA & $1(2.5 \%)$ \\
MS & \\
Board of pharmacy certification & $16(40 \%)$ \\
Ambulatory care & $9(22.5 \%)$ \\
Pharmacotherapy & $3(7.5 \%)$ \\
Ambulatory care and Pharmacotherapy & \\
\hline
\end{tabular}

Table 2 illustrates some of the characteristics of the clinics in the study. Most clinics were in Minnesota and were part of a patientcentered medical home (PCMH). While most clinics had CMM programs that had been established for several years, many clinics did not have a pharmacist present five days a week, or one full time equivalent (FTE). Many clinics were teaching clinics and had PharmD students in their practice completing rotations, as well as pharmacy residents which increased the number of pharmacists providing CMM on their team. 
Table 2. Demographics of participating clinics $(n=40)$

\begin{tabular}{|ll|}
\hline Characteristic & $\mathbf{N}(\%)$ \\
Practice location & $25(62.5 \%)$ \\
$\quad$ Minnesota & $10(25 \%)$ \\
North Carolina & $1(2.5 \%)$ \\
New Mexico & $3(7.5 \%)$ \\
New York & $1(2.5 \%)$ \\
$\quad$ Wisconsin & \\
Clinic is a certified patient-centered medical home $(\mathrm{n}=39)$ & $32(82 \%)$ \\
$\quad$ Yes & $7(18 \%)$ \\
$\quad$ No & $0.68 \pm 0.52$ \\
Pharmacist FTEs dedicated to clinic, mean \pm SD & $2009 \pm 5$ \\
Year CMM was first established at practice ( $\mathrm{n}=39)$, mean \pm SD & $8(20 \%)$ \\
Have P1-P3 students at practice & $34(85 \%)$ \\
Have 4th year PharmD students completing Advanced Pharmacy Practice & \\
Experiences (APPEs) & $22(55 \%)$ \\
Have PGY1 or PGY2 pharmacy residents & $24(61.5 \%)$ \\
\hline More than one pharmacist practicing on CMM team ( $\mathrm{n=39)}$ & \\
\hline
\end{tabular}

\section{Delivery of Pharmacy Services}

Table 3 illustrates how CMM visits were conducted in study sites. Two-thirds of sites were using health information technology to prospectively identify CMM patients, but fewer than half of sites had formal criteria that they utilized to identify patients for CMM. Initial CMM visits were typically scheduled for around one hour, while most sites scheduled follow-up visits for a half-hour. Most practices facilitated CMM referrals by including a process for electronic referral in the EMR. There was a lack of standardization of some aspects of the visit. For example, not all sites reported having a systematic process in place for categorizing MTP, or a standard way to document CMM visits. In addition, only half of the study sites had processes in place to assure quality of CMM services. Most sites had a written mission or vision for their CMM program, but not a written business plan or strategic plan. Finally, most sites applied a credentialing process for their pharmacists who provide $\mathrm{CMM}$, but not a privileging process.

Table 3. CMM Service Characteristics $(n=40)$

\begin{tabular}{|c|c|}
\hline Characteristic & $\mathbf{N}(\%)$ \\
\hline Approximate number of $\mathrm{CMM}$ visits at clinic within a week per FTE, mean \pm SD & $21.7 \pm 15.6$ \\
\hline $\begin{array}{l}\text { Clinic utilizes health information technology (e.g., EMR-generated lists of high risk patients, risk } \\
\text { stratification algorithms) to prospectively identify populations of patients who would benefit most } \\
\text { from CMM services }(n=39)\end{array}$ & $26(66.7 \%)$ \\
\hline $\begin{array}{l}\text { Formal criteria are in place (e.g., specific conditions, number of medications) that guide the } \\
\text { identification of patients most in need of CMM to then target patients for CMM services }\end{array}$ & $18(45 \%)$ \\
\hline Number of minutes initial CMM visits are typically scheduled, mean \pm SD & $49 \pm 15.2$ \\
\hline Number of minutes follow-up CMM visits are typically scheduled, mean \pm SD & $27.6 \pm 5.3$ \\
\hline $\begin{array}{l}\text { A process is in place that allows for electronic referral of patients from clinicians to pharmacists for } \\
\text { CMM services }\end{array}$ & $35(87.5 \%)$ \\
\hline $\begin{array}{l}\text { A systematic process for categorizing medication-related problems/drug therapy problems is } \\
\text { employed }\end{array}$ & $29(72.5 \%)$ \\
\hline $\begin{array}{l}\text { Always document in the electronic medical record a care plan (e.g., a SOAP note or related encounter } \\
\text { note) for each CMM visit }\end{array}$ & $39(97.5 \%)$ \\
\hline $\begin{array}{l}\text { CMM visits are documented in a medical record that is accessible by other clinicians/providers within } \\
\text { the clinic }\end{array}$ & $40(100 \%)$ \\
\hline The clinic has a standard format/template for recording CMM visits in the medical chart & $35(87.5 \%)$ \\
\hline \multicolumn{2}{|l|}{ A process is in place to assure the quality of CMM services delivered by pharmacists } \\
\hline Yes & $20(50 \%)$ \\
\hline Somewhat & $8(20 \%)$ \\
\hline No & $12(30 \%)$ \\
\hline Pharmacists lead or participate in medication-focused quality improvement initiatives & $24(60 \%)$ \\
\hline \multicolumn{2}{|l|}{$\begin{array}{l}\text { Have a written business plan or strategic plan for CMM program to support establishment of } \\
\text { sustainability within the organization }(n=31)\end{array}$} \\
\hline Yes & $11(35.5 \%)$ \\
\hline
\end{tabular}


Somewhat

No

A credentialing process for pharmacists who provide CMM is applied

A privileging process for pharmacists who provide CMM is applied $(n=33)$

Have a written mission and/or vision statement for your CMM practice separate from your clinic

mission/vision statement
$6(19.4 \%)$
$14(45.2 \%)$
$28(70 \%)$
$14(42.4 \%)$
$26(65 \%)$

Table 4 illustrates that there was considerable variation in applying the PPCP. For example, about a quarter of sites reported not always assessing all medications a patient is taking. In addition, many other steps of the patient care process are not always followed, including assessing the indication, effectiveness, safety, and adherence of every medication.

Table 4. Incorporation of various aspects of the CMM patient care process into CMM visits $(n=40)$

\begin{tabular}{|c|c|c|c|}
\hline $\begin{array}{l}\text { Throughout the course of working with a CMM patient (whether initial } \\
\text { or follow-up) the following are assessed: }\end{array}$ & Always & Sometimes & Never \\
\hline $\begin{array}{l}\text { The patient's medication experience (e.g., attitudes, beliefs, concerns, } \\
\text { and expectations of medication) recorded in the medical chart }\end{array}$ & $12(30 \%)$ & $28(70 \%)$ & $0(0 \%)$ \\
\hline $\begin{array}{l}\text { All medications the patient is taking (including prescription, } \\
\text { nonprescription, herbal, vitamins, and supplements) }\end{array}$ & $31(77.5 \%)$ & $9(22.5 \%)$ & $0(0 \%)$ \\
\hline The indication of every medication a patient is taking & $31(77.5 \%)$ & $9(22.5 \%)$ & $0(0 \%)$ \\
\hline $\begin{array}{l}\text { If the patient needs any medication(s) for a condition that is } \\
\text { NOT currently being treated or prevented }\end{array}$ & $26(65 \%)$ & $13(32.5 \%)$ & $1(2.5 \%)$ \\
\hline The effectiveness of every medication a patient is taking & $24(60 \%)$ & $16(40 \%)$ & $0(0 \%)$ \\
\hline $\begin{array}{l}\text { Side effects and/or adverse reactions of every medication a patient is } \\
\text { taking }(n=39)\end{array}$ & $25(64.1 \%)$ & $14(35.9 \%)$ & $0(0 \%)$ \\
\hline A patient's adherence to every medication & $27(67.5 \%)$ & $13(32.5 \%)$ & $0(0 \%)$ \\
\hline $\begin{array}{l}\text { Document individualized goals of therapy for each condition/medication } \\
\text { during a CMM encounter }\end{array}$ & 22 (55\%) & 17 (42.5\%) & $1(2.5 \%)$ \\
\hline
\end{tabular}

\section{Collaboration}

Table 5 demonstrates that most pharmacists in the study have developed CPAs for a variety of common conditions.

Table 5. Existing collaborative practice agreements (CPAs) (n=40)
\begin{tabular}{|ll|}
\hline $\begin{array}{l}\text { Collaborative practice agreements (CPA) } \\
\text { exist for the following conditions: }\end{array}$ & $\mathbf{N}(\%)$ \\
Anticoagulation & $12(30 \%)$ \\
Asthma & $18(45 \%)$ \\
COPD & $16(40 \%)$ \\
Depression & $12(30 \%)$ \\
Diabetes & $27(67.5 \%)$ \\
Dyslipidemia & $23(57.5 \%)$ \\
Flu/antiviral & $3(7.5 \%)$ \\
GERD & $11(27.5 \%)$ \\
Hypertension & $29(72.5 \%)$ \\
Hypothyroidism & $19(47.5 \%)$ \\
Pain & $15(37.5 \%)$ \\
Tobacco cessation & $26(65 \%)$ \\
Currently no CPAs are in place & $6(15 \%)$ \\
\hline
\end{tabular}


Pharmacists at these sites were utilizing support staff for a variety of CMM-related tasks. Table 6 shows that over half of all pharmacists use support staff for triaging phone calls, scheduling CMM visits, and billing for CMM services.

Table 6. Components of the CMM visit that pharmacists utilize support staff $(n=40)$

\begin{tabular}{|ll|}
\hline Utilize support staff for: & $\mathbf{N}(\%)$ \\
Scheduling & $39(97.5 \%)$ \\
Triaging phone calls & $27(67.5 \%)$ \\
Billing & $22(55 \%)$ \\
Performing point-of-care testing & $16(40 \%)$ \\
Enrolling patients in patient assistance programs & $13(32.5 \%)$ \\
Rooming patients & $13(32.5 \%)$ \\
Conducting follow-up phone calls & $10(25 \%)$ \\
Clinic staff do not support any of the above activities & $1(2.5 \%)$ \\
\hline
\end{tabular}

Table 7 describes the members of the care team pharmacists collaborate with and the level of collaboration they feel they have.

Table 7. Team members in the clinic the pharmacist collaborates with when providing CMM (n=40)

\begin{tabular}{|ll|}
\hline Collaborator & $\mathbf{N}(\%)$ \\
Physicians & $40(100 \%)$ \\
Other pharmacists & $32(80 \%)$ \\
Care managers & $31(77.5 \%)$ \\
Nurse practitioners & $31(77.5 \%)$ \\
Social workers & $27(67.5 \%)$ \\
Mental health & $26(65 \%)$ \\
Physician assistants & $26(65 \%)$ \\
Dieticians & $16(40 \%)$ \\
Pharmacy technicians & $12(30 \%)$ \\
Physical therapists & $4(10 \%)$ \\
The level of collaboration between pharmacists and other & \\
members of the health care team in clinic regarding CMM & \\
$\quad$ Excellent & $22(55 \%)$ \\
Good & $17(42.5 \%)$ \\
Fair & $1(2.5 \%)$ \\
Poor & $0(0 \%)$ \\
Very poor & $0(0 \%)$ \\
\hline
\end{tabular}

\section{Practice Management}

\section{Billing and Payment for CMM}

CMM programs engage in many different approaches to bill and obtain revenue, as demonstrated in Table 8 . While most pharmacists bill third party payers for CMM services, only about a third of CMM patient visits actually result in payment.

Table 8. CMM financial characteristics of participating clinics $(n=40)$

\begin{tabular}{|ll|}
\hline Characteristic & N (\%) \\
Payer mix of clinic overall by percentage* & $23.2 \% \pm 18.2$ \\
Medicare, mean \pm SD & $25.5 \% \pm 19.5$ \\
Medicaid, mean \pm SD & $7.65 \% \pm 13.7$ \\
Dual eligible, mean \pm SD & $37.6 \% \pm 23$ \\
Commercial (i.e., third party payer), mean \pm SD & $4.1 \% \pm 6.7$ \\
Uninsured/Self-pay, mean \pm SD & $2 \% \pm 5.9$ \\
Other, mean \pm SD & $40.7 \% \pm 30.0$ \\
Payer mix of patients receiving CMM by percentage* & $18.9 \% \pm 22.8$ \\
Medicare, mean \pm SD & $8.4 \% \pm 14.6$ \\
Medicaid, mean \pm SD & $27.4 \% \pm 26.0$ \\
Dual eligible, mean \pm SD & $2.9 \% \pm 7.4$ \\
Commercial (i.e., third party payer), mean \pm SD & \\
Uninsured/Self-pay, mean \pm SD & \\
\hline
\end{tabular}




\begin{tabular}{|c|c|}
\hline Other, mean \pm SD & $1.7 \% \pm 5.3$ \\
\hline \multicolumn{2}{|l|}{ Source of funding for providing CMM } \\
\hline Primary care medical practice & $5(12.5 \%)$ \\
\hline The health care organization (e.g., health system, clinically integrated network) & $27(67.5 \%)$ \\
\hline School or College of Pharmacy & $9(22.5 \%)$ \\
\hline Partnering entity & $1(2.5 \%)$ \\
\hline Other & $3(7.5 \%)$ \\
\hline $\begin{array}{l}\text { Billing third party payers for pharmacist services for pharmacist-provided patient care } \\
\text { services }\end{array}$ & $34(85 \%)$ \\
\hline Percent of CMM patients for whom pharmacists receive payment $(n=32)$, mean \pm SD & $33.83 \% \pm 33.28$ \\
\hline $\begin{array}{l}\text { Requirement that pharmacists have specific credentials or training beyond their pharmacy } \\
\text { degree by payers to whom pharmacists submit claims to provide payment }(n=32)\end{array}$ & $8(25 \%)$ \\
\hline
\end{tabular}

\section{Measuring CMM Outcomes}

Table 9 outlines the various measures that pharmacists indicated they are applying to CMM.

Table 9. Collected Measures Related to CMM ( $n=40)$

\begin{tabular}{|ll|}
\hline Measures Related to CMM & $\mathbf{N}(\%)$ \\
Number of medication-related problems identified & $30(75 \%)$ \\
$\begin{array}{l}\text { Number of medication-related problems resolved } \\
\text { Patient satisfaction }\end{array}$ & $27(67.5 \%)$ \\
$\begin{array}{l}\text { Patients meeting clinical goals (e.g., number of patients reaching hypertension, } \\
\text { diabetes goals) compared to baseline }\end{array}$ & $26(65 \%)$ \\
$\begin{array}{l}\text { Clinician satisfaction } \\
\text { Reduction in hospital readmissions }\end{array}$ & $22(55 \%)$ \\
$\begin{array}{l}\text { Achievement of pay-for-performance measures } \\
\text { Total cost of care savings }\end{array}$ & $14(35 \%)$ \\
$\begin{array}{l}\text { Reduction in hospital admissions } \\
\text { Impact on medical providers (e.g., satisfaction, relative value units) }\end{array}$ & $8(20 \%)$ \\
$\begin{array}{l}\text { Return on investment } \\
\text { Medication cost impact (whether savings or increases in cost attributed to } \\
\text { medications) }\end{array}$ & $7(17.5 \%)$ \\
$\begin{array}{l}\text { Change in medication adherence } \\
\text { Medication errors }\end{array}$ & $5(12.5 \%)$ \\
$\begin{array}{l}\text { Reduction in emergency room visits } \\
\text { Reduction in number of clinician visits }\end{array}$ & $5(12.5 \%)$ \\
$\begin{array}{l}\text { Change in ambulatory care resource utilization for defined groups of patients (e.g., } \\
\text { walk-in appointment requests, phone calls to triage) }\end{array}$ & $0(10 \%)$ \\
$\begin{array}{l}\text { Our clinical/practice tracks clinical/financial goals, but we do not separate these out } \\
\text { for patients receiving our CMM services versus others not receiving our services }\end{array}$ & $14(35 \%)$ \\
I/we are not tracking any measures to describe CMM impact in this clinic. & $3(7.5 \%)$ \\
\hline
\end{tabular}

Pharmacists collect data from a variety of sources. While most can use data from the EMR, almost half still rely on manual tracking data, as shown in Table 10.

Table 10. Collection of CMM data $(n=40)$

\begin{tabular}{|ll|}
\hline $\begin{array}{l}\text { Source of data used to support outcomes } \\
\text { assessment associated with CMM services }\end{array}$ & $\mathbf{N}(\%)$ \\
Electronic medical record & $35(87.5 \%)$ \\
Surveys & $23(57.5 \%)$ \\
Manual tracking & $18(45 \%)$ \\
Pharmacy claims data & $6(15 \%)$ \\
Medical claims data & $6(15 \%)$ \\
Do not currently collect any outcomes & $3(7.5 \%)$ \\
\hline
\end{tabular}




\section{KEY FINDINGS AND IMPLICATIONS}

The primary care pharmacists and sites highlighted in this report represent the characteristics of high performing CMM practices in a variety of settings. These data illustrate how CMM is being delivered in primary care and shed light on areas of inconsistency and opportunities for growth, as well as advancements that have been made in terms of CMM delivery, integration, and sustainability. Moving forward, there are a number of key points to consider when delivering CMM.

- Most sites do not have a full-time equivalent pharmacist.

- Implications: Part-time presence of a CMM pharmacist can be effective in balancing fiscal restraints and building sustainability. However, it may also limit the degree to which CMM can fully reach a population of need.

- Most sites schedule initial CMM visits for 60 minutes and follow-up visits for 30 minutes.

- Implications: While many visits with primary care providers are scheduled for 20 minutes, to perform a comprehensive assessment and create a care plan for a CMM patient requires significantly more time, both in the initial visit and during subsequent follow-up visits.

- Many clinics do not use formal criteria for identifying patients most in need of CMM.

- Implications: Without standard criteria for identifying patients most in need of CMM, there may be inconsistency in how patients are identified by both pharmacists and other health care providers. Identifying populations that would benefit from CMM may lead to enhanced value of CMM.

- Most practices have facilitated CMM referrals by including a process for electronic referral in the EMR.

- Implications: Electronic referral for CMM patients streamlines the process and fits in with referrals for other services, which may therefore lead to increased uptake of CMM.

- Over half of all study sites use support staff to assist in triaging CMM phone calls, scheduling CMM visits, and billing.

- Implications: Support staff can reduce time spent on administrative tasks, thus freeing up more time for pharmacists to provide CMM. However, there are several additional areas where support staff could be maximized, such as rooming patients and assisting with follow-up.

- Not all sites have adopted a consistent taxonomy for categorizing MTPs or a systematic process for documenting and monitoring resolution of MTPs.

- Implications: Using a standardized approach for categorizing medication therapy problems is a key component of producing fidelity in the care process for $\mathrm{CMM}$. It can help patients, providers, and other pharmacists better understand the PPCP. It can also support consistent delivery of care across pharmacists and help produce consistent outcomes from CMM services.

- Half of the study sites have adopted a process to assure the quality of CMM services delivered by pharmacists.

- Implications: Quality assurance is important to ensure standardization and quality of CMM. The experience of sites that have invested in the development of quality assurance systems for CMM can serve as models for the profession. The profession should also consider ways to support quality assurance in organizations where the number of practitioners committed to $\mathrm{CMM}$ service delivery may not effectively allow internally-based quality assurance systems.

- Pharmacists are not always consistently incorporating certain steps of the PPCP in their visits, such as evaluating indication, effectiveness, safety, and adherence of every medication.

- Implications: Consistently delivering CMM is of utmost importance. A consistent service needs to be delivered to ensure fidelity, achieve quality outcomes, and demonstrate the value of CMM across settings.

- Many sites are sustainably performing CMM services despite limited or even absent direct revenue from these services.

- Implications: As value-based payment systems grow, there is evidence that the impact of CMM on quality, cost, or other factors is as important, or possibly more important, than ensuring a revenue stream that fully supports CMM services. Those who are seeking to implement CMM should focus on a multi-faceted approach to establishing the business case for CMM services.

- Most pharmacists participating in this study were employed and funded directly by the host organization.

- Implications: While many clinical positions for pharmacists in primary care initially were established through academic partnerships through which the academic institution provided all or most of the salary support, the sites in this study have demonstrated that a value proposition can be established that justifies full funding for CMM services through a health care organization.

Practitioners building CMM practices frequently seek guidance on various aspects of service delivery, such as CPAs, billing, and quality assurance. This report provides an overview for those practitioners interested in building a CMM practice to guide care delivery and practice management, as well as those practitioners already providing CMM who wish to compare their practice to the sites involved in this cohort of mature CMM practices. 
Acknowledgements: This work was supported by the American College of Clinical Pharmacy (ACCP) and the ACCP Foundation through the grant Enhancing Performance in Primary Care Medical Practice through Implementation of Comprehensive Medication Management. The authors gratefully acknowledge all the pharmacists and primary care practices engaged in this study for their valuable work and insights.

\section{REFERENCES}

1. Watanabe JH, Mclnnis T, Hirsch JD. Cost of Prescription Drug-Related Morbidity and Mortality. Ann Pharmacother. 2018;52(9):829-837.

2. Carr, T. (2017). Too Many Meds? America's Love Affair With Prescription Medication. https://www.consumerreports.org/prescription-drugs/too-many-meds-americas-love-affair-with-prescription-medication/. Accessed January 15, 2018.

3. National Center for Health Statistics. Health, United States, 2016: With Chartbook on Long-term Trends in Health. Hyattsville, MD. 2017. https://www.cdc.gov/nchs/data/hus/hus16.pdf\#093. Accessed April 11, 2018.

4. American College of Clinical Pharmacy (ACCP). Standards of practice for clinical pharmacists. Pharmacotherapy 2014;34:794-7.

5. Saseen JJ, Ripley TL, Bondi D, et al. ACCP Clinical Pharmacist Competencies. Pharmacotherapy. 2017;37(5):630-636.

6. American College of Clinical Pharmacy. Comprehensive Medication Management in Team-Based Care How significant is the medication problem? https://www.accp.com/docs/positions/misc/CMM Brief.pdf. Accessed April 11, 2018.

7. Patient-Centered Primary Care Collaborative (PCPCC). The patient-centered medical home: integrating comprehensive medication management to optimize patient outcomes resource guide, 2nd ed. Washington, DC: PCPCC, 2012. www.pcpcc.org/sites/default/files/media/medmanagement.pdf. Accessed April 11, 2018.

8. McBane SE, Dopp AL, Abe A, et al. Collaborative drug therapy management and comprehensive medication management 2015. Pharmacotherapy. 2015;35(4):e39-e50.

9. Harris IM, Phillips B, Boyce E, et al. Clinical pharmacy should adopt a consistent process of direct patient care. Pharmacotherapy. 2014;34(8).

10. Boyce EG. The pharmacists' patient care process and more. Am J Pharm Educ. 2017;81(4):62.

11. Joint Commission of Pharmacy Practitioners. Pharmacists' patient care process. 2014. https://jcpp.net/wpcontent/uploads/2016/03/PatientCareProcess-with-supporting-organizations.pdf. Accessed April 11, 2018.

12. Snyder ME, Jaynes HA, Gernant SA, et al. Variation in medication therapy management delivery: Implications for health care policy. J Manag Care Spec Pharm. 2018;24(9):896-902.

13. Sorensen TD, Pestka DL, Sorge LA, Wallace ML, Schommer JC. A Qualitative Case Study Evaluation Defining Themes Producing Sustainability of Medication Management Services in Six Minnesota Health Systems. Am J Health Syst Pharm. 2016;73(5):307-314.

14. Cipolle RJ, Strand L, Morley P. Pharmaceutical Care Practice: The Patient Centered Approach to Medication Management. 3rd ed. McGraw Hill; 2012.

15. Kliethermes MA, Brown TR, American Society of Health-System Pharmacists. Building a Successful Ambulatory Care Practice: A Complete Guide for Pharmacists. American Society of Health-System Pharmacists; 2012.

16. Epplen KT. Patient care delivery and integration: Stimulating advancement of ambulatory care pharmacy practice in an era of healthcare reform. Am J Heal Pharm. 2014;71(16):1357-1365.

17. American Society of Health-System Pharmacists. Ambulatory Care Self-Assessment Tool. http://www.amcareassessment.org/. Accessed May 24, 2016.

18. McInnis, T. Capps, K. Get the medications right: a nationwide snapshot of expert practices-Comprehensive medication management in ambulatory/community pharmacy. Health2 Resources, May 2016. http://apptoget.com/wpcontent/uploads/2016/10/GetTheMedicationsRight.v22final-5.20.pdf. Accessed May 24, 2016. 